\title{
TRABALHO DOMÉSTICO: EVOLUÇÃO HISTÓRICA E OS IMPACTOS DA PANDEMIA DO COVID-r9
}

\author{
Gizelda Rodrigues de Araújo ${ }^{1}$ \\ Sônia Maria Rodrigues do Nascimento ${ }^{2}$
}

RESUMO: O referido trabalho parte do pressuposto de que a Lei N. 150/2015 veio dar nova roupagem à categoria, retirando aquele elo de aproximação dentro do núcleo familiar que antes existia, passando agora a vigorar como uma relação comercial. No entanto, questiona-se: Ante o crescimento normativo dessa categoria, quais os impactos causados para os empregados e empregadores domésticos frente à nova legislação vigente no mercado de trabalho em tempos de pandemia do covid-ı?? Para tanto, objetiva-se analisar os impactos causados pela pandemia do coronavírus nos empregados domésticos e os efeitos da legislação em meio a relação abalada entre empregado e empregador, bem como a evolução histórica dessa categoria. Utilizou-se de uma pesquisa bibliográfica com abordagem qualitativa e aponta como resultado: A Lei trouxe consigo um novo comando normativo, como a equiparação dos direitos para os trabalhadores domésticos com os demais empregados com empregos formais, impondo também os deveres tanto para uma parte quanto para a outra considerando de forma positiva, tais avanços. E no tocante a crise atual, a pandemia contribuiu para que a situação dessa categoria, estimada em mais de seis milhões de trabalhadoras, estão se sentindo divididas entre a recomendação de ficar em casa e se proteger, e a necessidade de sair para pagar contas.

Palavra- chave: Empregado doméstico. Direitos. Lei complementar 150/2015. pandemia do coronavirus.

ABSTRACT: This work is based on the assumption that Law N. 150/2015 has given a new look to the category, removing that link of approximation within the family nucleus that previously existed, now taking effect as a commercial relationship. However, the question is: Given the normative growth of this category, what are the impacts caused to domestic employees and employers in view of the new legislation in force in the labor market in times of the covid-I9 pandemic? Therefore, the objective is to analyze the impacts caused by the coranavirus pandemic on domestic

\footnotetext{
${ }^{1}$ Pós-graduada em Biologia(UFLA); Pós-graduada em Métodos e técnicas de ensino (UNIVERSO); Pós graduada em Gestão ambiental (FASEM); Pós-graduanda em Direito Civil (PUC- Minas); Graduada em Pedagogia (UEG); Graduada em Licenciatura em Física(UFG); Graduada em Biologia (UEG); Graduanda em Bacharelado em Direito (UEG).

2 Pós-graduação Lato sensu em Planejamento Educacional.- Universidade Salgado de Oliveira UNIVERSO; Pós-graduação Lato sensu em Direito e processo do trabalho - Universidade anhanguera UNIDERP; Pós-graduação Lato sensu em Advocacia trabalhista - Universidade Salgado de Oliveira UNIVERSO; Licenciatura em Pedagogia - Universidade Católica de Goiás - PUC; Bacharel em Direito - Universidade Salgado de Oliveira UNIVERSO.
} 
workers and the effects of the legislation amid the shaken relationship between employee and employer, as well as the historical evolution of this category. A bibliographical research with a qualitative approach was used and points out as a result: The Law brought with it a new normative command, such as the equalization of rights for domestic workers with other employees with formal jobs, also imposing duties both for a party and for the other considering positively such advances. And with regard to the current crisis, the pandemic has contributed to the situation of this category, estimated at more than six million workers, feeling torn between the recommendation to stay home and protect themselves, and the need to go out to pay bills.

Keyword: Domestic employee . Rights. Complementary Law 150/2015. Coronavirus. Pandemic.

\section{INTRODUÇÃO}

$\mathrm{O}$ ano de 2020 foi marcado pela insurgência de uma doença que se transformou em pandemia conforme atesta a Organização Mundial de Saúde $(\mathrm{OMS})^{3}$.

Neste contexto do Covid-19 ${ }^{4}$, foram afetados todos os setores que necessitam de aglomeração social, como clubes, igrejas, supermercados, shoppings, educação e outros.

Os impactos da pandemia efetivados pelo novo Coronavírus (Covid-19) tem se mostrado alarmantes, segundo dados levantados pela Organização das Nações Unidas (UNESCO) ${ }^{5}$, visto que a pandemia afeta a saúde pública de forma agressiva,

\footnotetext{
${ }^{3}$ Organização Mundial de Saúde é uma agência especializada em saúde, fundada em 7 de abril de 1948 e subordinada à Organização das Nações Unidas. Sua sede é em Genebra, na Suíça. O diretor-geral é, desde julho de 2017, o etíope Tedros Adhanom. A OMS tem suas origens nas guerras do fim do século XIX (In: Wikipédia, 202I).

4 "O coronavírus são uma grande família de vírus comuns em muitas espécies diferentes de animais, incluindo camelos, gado, gatos e morcegos. Raramente, o coronavírus que infectam animais podem infectar pessoas, como exemplo do MERS-CoV e SARS-CoV. Recentemente, em dezembro de 2or9, houve a transmissão de um novo coronavírus (SARS-CoV-2), o qual foi identificado em Wuhan na China e causou a COVID-rg, sendo em seguida disseminada e transmitida pessoa a pessoa. A CovidI9 é uma doença causada pelo coronavírus, denominado SARS-CoV-2, que apresenta um espectro clínico variando de infecções assintomáticas a quadros graves. De acordo com a Organização Mundial de Saúde, a maioria (cerca de 80\%) dos pacientes com COVID-19 podem ser assintomáticos ou oligossintomáticos (poucos sintomas), e aproximadamente $20 \%$ dos casos detectados requer atendimento hospitalar por apresentarem dificuldade respiratória, dos quais aproximadamente $5 \%$ podem necessitar de suporte ventilatório" (BRASIL, 202I).

5 "A Organização das Nações Unidas para a Educação, a Ciência e a Cultura (UNESCO) (acrônimo de United Nations Educational, Scientific and Cultural Organization) é uma agência
} 
tirando vidas não apenas do grupo de risco - os idosos -, mas de crianças, jovens e adultos.

As medidas adotadas de isolamento e distanciamento por todos os países, para manter a população em casa, tencionam a economia do país refletindo na paralisação de distintos serviços, dentre eles o dos empregados domésticos.

Devido ao surto do coronavirus, em que a situação está restrita ao isolamento social, a relação entre empregados domésticos e empregadores foi abalada.

Segundo nota do Jornal Hoje de 18/03/2020, em entrevista com José Avelino, Presidente do Instituto doméstico Legal, o Brasil estava nesta data com mais de 6 milhões de trabalhadores domésticos divididos entre a recomendação de ficar em casa e se proteger e a necessidade de sair e trabalhar para pagar as contas. Já os empregadores se viram diante de um impasse: dispensar a empregada, uma vez que estavam trabalhando home office e também cumprindo as recomendações de isolamento. Mas por outro lado, dispensar a empregada seria o efeito colateral da pandemia, visto que muitos empregadores perderam emprego ou diminuíram a renda. O que seria mais recomendável? $\mathrm{E}$ as leis trabalhistas inerentes a Lei $\mathrm{N}$. $150 / 2015$ amparam tais procedimentos?

De acordo com os dados fornecidos pelo $\operatorname{COEP}^{6}$, de 22/10/2020, são 4,7 milhões de profissionais em todo o país, sendo que a maioria são mulheres negras. Nestes meses de isolamento social, mais de 1,2 milhões e postos de trabalho domésticos foram fechados, agravando ainda mais a situação financeira dessas profissionais.

Percebe-se com isso que a pandemia do coronavirus afetou, e muito, os trabalhadores domésticos

O trabalho doméstico está presente no seio da sociedade brasileira desde a época da escravidão. Trabalho este que na grande maioria eram realizados por mulheres que desenvolviam as tarefas domésticas muitas vezes em troca de moradia,

especializada das Nações Unidas (ONU) com sede em Paris, fundada em i6 de novembro de 1945 com o objetivo de contribuir para a paz e segurança no mundo mediante a educação, ciências naturais, ciências sociais/humanas e comunicações/informação" (In: Wikipédia, 202ı. Grifos do original).

${ }^{6}$ http://coepbrasil.org.br/trabalhadoras-domesticas-desemprego-e-precarizacao-e-realidade-durantea-pandemia 
vestuário e alimentação ou por menos que um salário-mínimo. Mas, de acordo com Avelino(2015, p. 15), "O mundo mudou e os empregados domésticos também. Já foi o tempo em que o empregado trabalhava vinte ou trinta anos na casa do mesmo empregador e se aposentava sem direitos, analfabeto e desinformado"

Com o dinamismos social, esse quadro também evoluiu, ainda que de forma tímida na parte juridica, mas foi apresentado a cada conquista avanços siguinificativos para a classe dos trabalhadores domésticos no Brasil, através de Leis, Decretos, Emenda Constitucional, sindicatos, etc.

A Lei em comento N. 150/2015 veio dar nova roupagem à categoria, retirando aquele elo de aproximação dentro do núcleo familiar que antes existia, passando agora a vigorar como uma relação comercial. No entanto, vale questionar: Ante o crescimento normativo dessa categoria, quais os impactos causados para os empregados e empregadores domésticos frente à nova legislação vigente no mercado de trabalho em tempos de pandemia do covid-ig?

Diante dos fatos em tela, objetiva-se analisar os impactos causados pela pandemia do coronavírus nos empregados domésticos e os efeitos da legislação em meio a relação abalada entre empregado e empregador.

\section{Evolução histórica do direito do trabalho doméstico no brasil.}

Segundo Souza Junior (2015, p. 19), com a chegada dos descobridores do Brasil, vieram com eles os negros para emprestarem em regime de escravidão, sua força de trabalho. Mesmo após a libertação dos escravos em I3 de Maio de I888, os negros sem preparação para uma vida sem correntes, continuaram na dependência dos trabalhos que antes executavam.

O trabalho doméstico era regido pelas normas gerais do código civil, o qual não previa qualquer segurança ou garantia para o trabalhador e somente em I94I, com a outorga do Decreto Lei 3.078, que tinha como objetivo tutelar os direitos dos empregados domésticos, emerge a preocupação com o respeito à dignidade das pessoas envolvidas na relação de trabalho.

No entanto, nem de longe, esses direitos adquiridos se aproximavam dos direitos dos trabalhadores urbanos contidos na Consolidação dos Direitos dos 
Trabalhadores -(CLT) de I.943, pois a mesma retrocedeu no campo de regulamentação do empregado doméstico, conforme reza o artigo $7^{\circ}$ da CLT:

\begin{abstract}
Art. $7^{\circ}$ - Os preceitos constantes da presente Consolidação salvo quando for em cada caso, expressamente determinado e contrário, não se aplicam: aos empregados domésticos, assim considerados, de um modo geral, os que prestam serviços de natureza não econômica à pessoa ou à família, no âmbito residencial destas.(CLT, 1943)
\end{abstract}

Nota-se que os empregados domésticos mesmo não sendo amparados pela CLT, ainda assim continuavam regidos pelo Decreto Lei 3.078 de I94I.

Após 1943, surgiram outras leis e decretos que beneficiavam de alguma forma o empregado doméstico.

De acordo com Carlos Henrique Bezerra Leite, em I.972, criaram a Lei, (Lei Especial), N. 5.859/ 72 que previa: férias anuais remuneradas de 20 dias úteis; filiação à previdência social como segurado obrigatório, anotação na Carteira de Trabalho e Previdência Social - CTPS.

Com a promulgação da Constituição Federal de 88, ampliou - se o rol dos direitos desses trabalhadores passando assim, a ter alguns direitos fundamentais como: salário mínimo, irredutibilidade do salário, salvo o disposto em convenção ou acordo coletivo, décimo terceiro salário, repouso semanal remunerado, preferencialmente aos domingos, férias anuais com pelo menos, um terço a mais do que o salário normal, licença a gestante, sem prejuízo do emprego e do salário, licença -paternidade no ternos fixados em lei (ADCT, art. Io, $\S^{\mathrm{I}^{\circ}}$ ); aviso prévio proporcional ao tempo de serviço trabalhado, sendo no mínimo trinta dias, nos termos da lei e aposentadoria, todos previstos no art. $7^{\circ}$ da CF/88.

Após a CF/88, a Lei II.324/2006, ampliou os direitos desses trabalhadores contidos na Lei N. 5.859/72, acrescentando o direito de não ser descontado a alimentação, vestuário, higiene, moradia; Assegurou o direito às férias anuais remuneradas de trinta dias com pelo menos $\mathrm{I} / 3$ a mais que o salário normal após cada período de doze meses de trabalho prestado a mesma pessoa; Estendeu a proteção a gestante, quando esta for demitida sem justa causa garantindo-lhe a estabilidade no emprego desde a confirmação da gravidez até cinco meses após o parto. 
Já a Lei N. 10.208/200I, acrescentou o art. $3^{\circ}$ da Lei $n^{\circ}$ 5.859/72, facultando a inclusão do Fundo de Garantia do Tempo de Serviço e o Seguro desemprego para os que estava incluído no FGTS.

Quanto a Lei n. 12.964/2014, ampliou no art. 6으 E á Lei no 5.859/72 a aplicação das multas previstas na CLT ao regime do trabalho doméstico.

Com a Emenda Constitucional N. 72/2013, que modificou por completo a composição do Parágrafo Único do artigo $7^{\circ}$ da Constituição Federal de 1988, cujo objetivo maior seria nivelar os direitos já existentes contidos na Carta Magna trazendo-os para os domésticos do nosso país na expectativa de minimizar a exclusão dos direitos sociais à essa pequena parcela da sociedade trabalhadora.

Por fim, o artigo 46 da Lei N. 150 de primeiro de junho de 2015, revogou a Lei $\mathrm{n}$ - $5.859 / 72$, dando origem a um único instituto capaz de regular as relações de trabalho dos profissionais em relevo.

A Lei Complementar também trouxe novas regras relativas ao Fundo de Garantia por Tempo de Serviço (FGTS) devido ao empregado doméstico são basicamente iguais àquelas aplicáveis aos demais trabalhadores. A diferença reside na multa havida em caso de rescisão contratual imotivada, o que segundo Ricardo Rezende(2016, p. 133), nos casos de empregados regidos pela CLT, o empregador deverá pagar uma multa no valor de 50\% do valor depositado, sendo $40 \%$ destinado ao empregado e ıо\% à União (Lei Complementar Iı/200I) e, no caso trabalho doméstico, o empregador fica obrigado a recolher mensalmente a importância de 3,2\% da remuneração a título de multa de FGTS.

Vale ressaltar que a Lei Complementar 150/2015 modificou por completo todo o arcabouço jurídico passando a ter um novo formato demonstrando as novas conquistas principalmente para a emancipação social nas relações empregatícias dessa categoria profissional que há muito tempo era reservado apenas o direito ao salarial, irredutibilidade salarial, décimo terceiro salário, repouso semanal, gozo de férias, licença maternidade e paternidade, aviso prévio e aposentadoria.

O novo cenário veio garantir a igualdade constitucional. Surgiu assim uma Lei específica, capaz de regular as relações de trabalho garantindo os direitos e deveres já elencados pela Emenda Constitucional 72/2013. Observado as 
peculiaridades do trabalho doméstico quando houver omissão na própria lei, aplicando-se de forma subsidiária a Consolidação das Leis do trabalho (CLT).

Além disso, desmistificou por completo a confusão que existia na definição da configuração entre empregado e diarista.

Conceituou empregado doméstico como sendo aquele que presta serviços de forma continua, subordinada, onerosa e pessoal e de finalidade não lucrativa à pessoa ou à família, no âmbito residencial destas, por mais de 2( dois ) dias por semana.

Dentre as várias modificações trazidas pela nova lei, cita-se algumas como a proibição do menor de 18 anos para realizar trabalhos domésticos; A duração do trabalho que não excederá a 8 horas diárias e 44 semanais; A remuneração do adicional de horas extras com no mínimo 50\% superior o valor da hora normal, bem como a compensação de horas através de acordo escrito entre empregado e empregador; A duração do tempo de serviço, o tempo de repouso, os feriados e as horas não trabalhadas quando o trabalhador morar no emprego, não se considera como horário de trabalho, bem como quando o empregado viaja com o empregador serão considerado apenas as horas trabalhadas no período mediante acordo escrito e com o percentual de $25 \%$ superior o valor do salário hora;

O controle do horário pelo empregador, diferente da regra da CLT artigo 74, $\S 2^{-}$que exige mais de io trabalhadores no estabelecimento; Intervalo intrajornada para repouso e alimentação de I hora no mínimo e no máximo 2 horas sendo que para os que moram no emprego esse intervalo poderá ser dividido em dois períodos desde que cada um deles tenha no mínimo i hora e no máximo 4 horas por dia.

A lei acrescenta ainda o adicional noturno com acréscimo de $20 \%$ sobre o valor da hora diurna, onde o horário noturno é considerado das 22 horas às 5 horas e com a devida redução ficta da hora noturna de 52 minutos e 30 segundos; Descanso semanal remunerado de preferência aos domingos e também nos feriados e as férias poderão ser divididas em até dois períodos, mas um não poderá ser inferior a quatorze dias corrido, é também uma faculdade do trabalhador converterı/3 das férias em abono pecuniário, bem como é licito ao mesmo permanecer no local de trabalho desde que more no emprego; 
Já para o regime de tempo parcial, cuja duração não exceda a 25 horas semanais, entretanto poderá ser acrescida de forma suplementarem até I hora através de acordo escrito entre as partes com limite máximo de 6 horas diárias e será pago de forma proporcional ao tempo trabalhado e após 12 meses de vigência do contrato de trabalho, o empregado terá direito a férias proporcionais de acordo com o que determina a Lei em seu artigo $3^{\circ}, 3^{\circ}$, I, II, III, IV, V, VI, entre outros benefícios em vigor.

Tem- se um novo quadro garantidor dos Direitos e Garantias fundamentais nas normas domésticas em nossa sociedade, com princípios fundamentais como o respeito à dignidade da pessoa humana e a valorização social do trabalho.

\section{Sujeitos da relação do trabalho doméstico}

Segundo Antônio Umberto de Souza Júnior ${ }^{7}(2015)$, a palavra doméstico vem Do latim domus (casa), sendo utilizado, como substantivo, para designar os serviçais que executam tarefas no interior da casa e, como adjetivo, para qualificar "toda espécie de trabalho manual ou serviço executado dentro de um lar, para atender as necessidades diárias das pessoas que nele habitam, como para trazê-lo sempre em ordem e arrumação"

A lei N. 150/2015, em seu artigo Io-define o trabalhador doméstico como:

$$
\begin{aligned}
& \text { Art. Io } \text {. Ao trabalhador doméstico, assim considerado aquele que presta } \\
& \text { serviços de forma continua, subordinada, onerosa e pessoal e de finalidade } \\
& \text { não lucrativa à pessoa ou à família, no âmbito residencial destas, por mais } \\
& \text { de } 2 \text { ( dois ) dias por semana, aplica-se o disposto nesta Lei. } \\
& \text { (Complementar, Lei } 150 / 2015 \text { ). }
\end{aligned}
$$

Com a definição do empregador doméstico inserido no artigo primeiro da Nova Lei N. 150/2015, nele encontra-se também os requisitos caracterizadores de identificação desse trabalhador como: Pessoalidade que significa dizer o empregado deve prestar pessoalmente o serviço, “instituitu personae”, assim como em todos os

\footnotetext{
7 Antonio Umberto de Souza Júnior é Mestre em Direito e Doutorando em Ciências JurídicoPolíticas, Professor e Coordenador Acadêmico dos Cursos de Especialização em Direito e Processo do Trabalho do IDP - Instituto Brasiliense de Direito Público e da Atame Pós-Graduação, Professor do UniCEUB e da ENAMAT - Escola Nacional de Formação e Aperfeiçoamento dos Magistrados do Trabalho, Juiz Titular da 6 $\underline{\text { a }}$ Vara do Trabalho de Brasília, ex-Conselheiro do Conselho Nacional de Justiça (2007-2009) e empregador doméstico há 25 anos.
} 
contratos trabalhistas significa dizer que a prestação do serviço é prestado pela própria pessoa; Continuidade caracterizada pela nova lei como sendo os serviços prestados por mais de dois dias por semana e, portanto não fixado em horas e sim em dia inteiro, não excedente a 8 h diárias e 44 semanais; A subordinação é jurídica, vez que é o empregador quem dirige a prestação pessoal de serviço; Onerosidade quer dizer que o trabalho prestado tem como contraprestação o receber a remuneração, ou seja não é gratuito.

Segundo Carlos Henrique Bezerra Leite ${ }^{8}$ (2015), "empregador doméstico é aquele que contrata trabalhador doméstico", tendo como requisitos necessários: ser uma pessoa física plenamente capaz com dezoito anos completo ou o relativamente incapaz aquele que tem de dezesseis a dezoito anos, desde que assistido por responsável legal ou emancipado como determina o artigo $5^{\circ}$. caput, e Parágrafo Único do Código Civil; ou família e morar em local destinado à sua residência e não explorar atividade econômico-lucrativo.

No entender de Garcia (2014, p.235) "O empregador doméstico, portanto, não é uma empresa, não exercendo atividades econômicas ou lucrativas, mas sim é a pessoa natural ou a família”.

Assim, no conceito jurídico, jamais poderão ser enquadrados como empregadores domésticos os empresários, empresa individual de responsabilidade individual, sociedade empresária, individual ou coletiva, os profissionais liberais, instituições de beneficência, etc. basicamente por explorarem atividade econômicolucrativo.

A Lei trouxe consigo um novo comando normativo, como a equiparação dos direitos para os trabalhadores domésticos com os demais empregados com empregos formais, impondo também os deveres tanto para uma parte quanto para a outra.

Dentro dessa estrutura, encontra-se atribuído especificamente ao empregado os deveres de apresentar a Carteira de trabalho e Previdência Social no momento em que for admitido, bem como atestado de boa conduta, de saúde a critério do

\footnotetext{
${ }^{8}$ Carlos Henrique Bezerra Leite

Advogado e Consultor jurídico. Doutor e Pós-Doutor em Direito. Recursos Trabalhistas.
} 
empregador; Executar os trabalhos para os quais foram contratados; Não faltar; Ser pontual; Assinar os recibos de pagamento; Avisas com trinta dias de antecedência sua saída do emprego; Manter o sigilo e a privacidade da família do empregador; Tratar empregador e demais familiares com respeito e educação.

Nesse sentido, os avanços são considerados de forma positiva do ponto de vista de uma sociedade empregatícia que negligenciava os direitos básicos de proteção dos trabalhadores domésticos quando lhes foi negado os fundamentos da valorização do trabalho humano e da dignidade da pessoa humana. Assim, tanto o empregado quanto o empregador a partir da PEC das domésticas adquiriram ao longo dessa jornada a equiparação global dos direitos e com todas as suas vantagens como demonstra o crescimento norteado pela lei 150/2015.

\section{Trabalhador doméstico em tempos de coronavírus}

A pandemia do novo coronavírus chegou abruptamente em 2019/2020 e vai marcar uma época, provocando mudanças acentuadas e adaptações inevitáveis do modo de viver, de produzir, de consumir com muitas repercussões no mundo do trabalho e na regulação dos direitos trabalhistas. (TUPINAMBÁ,2020,p.I44).

No início do mês de março de 2020, a pandemia alcançou o Brasil e com esse cenário, inevitavelmente, o setor econômico $e$ as relações de trabalho foram impactadas, de modo que foi necessária a adoção de medidas por parte do Governo Federal com o intuito de minimizar os efeitos negativos, através da Medida Provisória $\mathrm{n}^{\mathrm{0}} 927 / 2020$.

Contudo, segundo Tupinambá(2020), já se vislumbra nas cogitações do momento que não haverá o desejado retorno ao normal, uma vez que estamos ingressando inevitavelmente no desconhecido território de um novo normal. Em vez de continuar percorrendo os caminhos habituais que proporcionavam relativa segurança, teremos que avançar enquanto desbravamos trilhas ignoradas, superando obstáculos, construindo pontes com o desconhecido e encontrando soluções adequadas para uma nova etapa civilizatória 
Nesta senda, vale ressaltar sobre a empregada doméstica que mesmo após os decretos estaduais que permitiram o funcionamento apenas dos serviços essenciais, a empregada doméstica passa por uma delicada situação nessa pandemia de covid-ı.

Nesse caso, o respeito ao lockdown ${ }^{9}$ depende dos contratantes e das medidas do governo estadual, visto se tratar de um serviço realizado no ambiente familiar e privado. Dessa maneira, segundo informes do "blog doméstica.com", a doméstica pode continuar prestando seus serviços desde que sejam imprescindíveis aos cuidados de crianças, idosos e debilitados.

Observa-se que a categoria das trabalhadoras domésticas é particularmente vulnerável na crise do coronavírus, uma vez que, têm sido expostas sistematicamente a riscos de contaminação sem poderem se isolar.

De acordo com reportagem de Maria Martha Bruno no site da UOL Economia, ${ }^{\text {Io }}$ com o fim do auxilio emergencial, a situação piora e deixa desamparada a categoria, estimada em mais de seis milhões de trabalhadoras, que nesse tempo de coronavírus estão se sentindo divididas entre a recomendação de ficar em casa e se proteger, e a necessidade de sair para pagar contas, segundo reportagem de Mário Avelino, Presidente do Instituto doméstico Legal no dia 18/03/2020, em entrevista com ao Jornal Hoje.

Ainda de acordo com Mario Avelino (' 2020 ) prevê-se negociações entre empregados e empregadores no sentido de férias antecipadas ou licença remunerada com algum tipo de compensação futura, podendo fazer horas extras, trabalhar sábado e domingo, de acordo como combinado.

\footnotetext{
9 Lockdown significa "bloqueio total” ou “confinamento". É adotado em situações extremas, como uma pandemia, e restringe o movimento de pessoas e cargas. A quebra do isolamento só é permitida em situações emergenciais. https://blog.idomestica.com/5135/empregada-domestica-situacaolockdown\#.YHlrm2dKiUk

${ }^{10}$ https://economia.uol.com.br/reportagens-especiais/vulnerabilidade-domesticas-pandemia/\#cover

II Um dos maiores especialistas em Emprego Doméstico e FGTS do Brasil, Mario Avelino é administrador de empresas e analista de sistemas com mais de 46 anos de experiência em Departamento Pessoal e desenvolvimento de sistemas de Folha de Pagamento para grandes empresas. Há mais de 31 anos dedica-se a pesquisa e estudos sobre Fundo de Garantia do Tempo de Serviço FGTS e o I4 anos em Emprego Doméstico.

Mario Avelino é fundador e Presidente da empresa Doméstica Legal e das ONGs Instituto Doméstica Legal e Instituto Fundo Devido. Representando o IDL, Avelino atua em Brasília discutindo e apresentando projetos para incentivar a formalização do Emprego Doméstico. marioavelino.com.br/mario-avelino/
} 
No tocante aos acidentes e doenças provenientes da atividade laboral, ainda que não regulado expressamente pela LC 150, mas aplicando-se subsidiariamente a CLT, empregador e trabalhador domésticos, assim como o Estado e a sociedade, têm o dever de preservar o meio ambiente, incluído o do trabalho (CF, arts. 225 e 200, VIII).

A LC 150/2015 não regulamentou expressamente o direito dos trabalhadores domésticos à "redução dos riscos inerentes ao trabalho, por meio de normas de saúde, higiene e segurança" (CF, art. $7^{\circ}$, XII), e a previsão do "seguro contra acidentes de trabalho, a cargo do empregador, sem excluir a indenização a que este está obrigado, quando incorrer em dolo ou culpa" (CF, art. $7^{\circ}$, XXVIII).

Todavia, o art. 37 da LC 150/2015, alterou o § I ${ }^{\circ}$ do art. I8 e o art. I9 da Lei 8.213, de 24 de julho de 199I, que passaram a vigorar com as seguintes redações:

Art. $18(\ldots)$

§ I o Somente poderão beneficiar-se do auxílio-acidente os segurados incluídos nos incisos I, II, VI e VII do art. II desta Lei, o qual confere no item II da Lei 8.213/91 condição de segurado ao doméstico obrigatório da Previdência Social e o § I $\mathrm{o}$ do art. I8 da mesma lei lhe estende o direito ao benefício do auxílio-acidente, razão pela qual entendemos que as normas supracitadas regularam, por via transversa,(BRASIL,LC I50/2015)

Assim, pela interpretação sistemática e teleológica de todos os dispositivos constitucionais e infraconstitucionais acima mencionados, parece-nos que o empregador doméstico poderá ser responsabilizado pelos danos - materiais e/ou morais - causados aos seus trabalhadores domésticos no meio ambiente laboral doméstico.

Por não ser o ambiente doméstico uma atividade de risco, a responsabilidade do empregador doméstico por acidentes do trabalho deverá ser, em regra, subjetiva (CF, art. 7º, XXVIII, c/c art. 927,parágrafo único do CC). (LEITE,2018, p.187).

Nesse diapasão, observa-se que o fato do empregador ser responsabilizado pelos acidentes que causem danos à saúde do empregado, se veja obrigado a afastar este, em virtude de arcar futuramente com possível contaminação do covid-ı.

Com o intuito de evitar uma contaminação pelo covid-ı, muitas famílias dispensaram os empregados domésticos, que agora engrossam a fila dos desempregados. 
O impacto causado pela pandemia no mercado de trabalho, segundo Instituto Brasileiro de Estatística e Geografia-(IBGE), mostra que o trabalho doméstico foi o segundo setor mais atingido no país. E segundo a Pnad Contínua, divulgada em 28 de Janeiro de 202I, I,5 milhão de postos de trabalho doméstico foram perdidos de setembro a novembro de 2020, último período analisado.

Segundo dados do "Estadão" do dia 22 de Março de 2021, as domésticas estão no grupo dos mais atingidos pela crise econômica da pandemia, visto que ao longo de 2020 I,2 milhões de pessoas nessa atividade, perderam o emprego, de acordo com pesquisa do IBGE, esses dados equivalem a $16 \%$ do total de vagas fechadas no ano passado entre formais e informais, acrescentando ainda que a piora da pandemia pode ser um obstáculo para esse pessoal, sendo mais uma fonte da pobreza, principalmente entre as famílias lideradas por mulheres.

As trabalhadoras que perderam o emprego, encontraram no auxílio emergencial ${ }^{13}$ uma ajuda para sobreviver, mas o valor da transferência de renda foi reduzido de $\mathrm{R} \$ 600,00($ seiscentos reais) para $\mathrm{R} \$ 300,00$ (trezentos reais), piorando ainda mais o quadro .

O auxílio emergencial 2021 já está valendo como Medida Provisória (I.039/202I) e os requisitos são os mesmos do ano passado. No entanto, o benefício que vigorou a partir de abril do ano passado, não abarcou todos aqueles que se inscreveram no CadÚnico e com isso muitos perderam o favorecimento.

As domésticas que tiveram um contrato vigorando ${ }^{14} \mathrm{e}$ carteira de trabalho assinada não poderão ser favorecidas pelo auxílio emergencial em 2021. Porém, aquelas que tiveram seus contratos suspendidos pela MP $936{ }^{15}$ ou já estão em situação

\footnotetext{
${ }^{12} \mathrm{O}$ Estado de S. Paulo, também conhecido como Estadão, é um jornal brasileiro publicado na cidade de São Paulo desde 1875. Ao lado de O Globo, Folha de S. Wikipédia

${ }^{13} \mathrm{O}$ Auxílio Emergencial 202ı é um benefício financeiro concedido pelo Governo Federal destinado às pessoas que receberam Auxílio Emergencial e Auxílio Emergencial Extensão, e que atendiam aos critérios dos Programas em dezembro de 2020, e tem por objetivo fornecer proteção emergencial no período de enfrentamento à crise causada pela pandemia do Coronavírus - COVID 19.

${ }^{14} \mathrm{https} / / /$ blog.idomestica.com/5152/auxilio-emergencial-202I-domestica\#.YM_C6GhKiUk

is institui o programa emergencial de manutenção do emprego e da renda e dispõe sobre medidas trabalhistas complementares para enfrentamento do estado de calamidade pública reconhecido pelo decreto legislativo no 6 , de 20 de março de 2020, e da emergência de saúde pública de importância internacional decorrente do coronavírus (covid-19), de que trata a lei no ${ }^{33.979}$, de 6 de fevereiro de 2020 , e dá outras providências-
} 
de informalidade e receberem mensalmente no máximo $\mathrm{R} \$ 550$,oo(por familiar no domicílio) poderão gozar do benefício.

De acordo com Luana Pinheiro, pesquisado do Instituto de Pesquisa Econômica Aplicada (IPEA), que estuda o trabalho doméstico, lembra que a falta de vínculo empregatício deixa essas trabalhadoras mais vulneráveis e facilita as demissões, complementando ainda que, o recrudescimento da pandemia e o aperto na renda das famílias que contratam os serviços deverá dificultar a retomada das vagas perdidas.

Sabendo que o trabalho doméstico ainda hoje é uma das principais ocupações entre as mulheres, que são a maioria em todo mundo, cerca de $80 \%$ e que no Brasil ainda permanece sendo a principal fonte de emprego, respondendo por 6,8\% dos empregos no país, segundo Claire Hobden, especialista em trabalhadores vulneráveis da OIT, a vulnerabilidade dessas empregadoras domésticas, aumenta com a pandemia.

\section{CONCLUSÃO}

A Lei Complementar 150/2015 pareceu atentar para esse problema e, indubitavelmente, é um marco normativo que inaugurou um novo cenário para os domésticos ao incluir regras de abertura do sistema jurídico atinentes às relações que envolvem esse tipo trabalho, possibilitando expressamente a aplicação subsidiária da CLT, além de abordar diversos temas de ordem trabalhista, fiscal, previdenciária e administrativa. Diante dessa nova realidade, pode-se afirmar que a lei trouxe um comando normativo em que esses profissionais passam a ter direitos, ainda não equiparados, mas muito aproximados dos demais trabalhadores urbanos.

Além disso, desmistificou por completo a confusão que existia na definição da configuração entre empregado e diarista.

E, diante da crise do coronavirus, vale ressaltar sobre a empregada doméstica que mesmo após os decretos estaduais que permitiram o funcionamento apenas dos serviços essenciais, a empregada doméstica passa por uma delicada situação nessa pandemia de covid-ı. Observa-se que a categoria das trabalhadoras 
domésticas é particularmente vulnerável na crise do coronavírus, uma vez que, têm sido expostas sistematicamente a riscos de contaminação sem poderem se isolar.

Por outro lado, muitas perderam seus empregos ficando à mercê do auxílio emergencial que visivelmente não supre as necessidades das mesmas, uma vez que a maior da parte dos empregados domésticos são mulheres e arrimo da família, segundo dados da OIT(2017).

\section{REFERÊNCIAS}

BRASIL, Constituição da República Federativa do Brasil de 1988. Disponível em: http:/www.planalto.gov.br/ccivil_03/Constituicao/Constituicao.htm. Acesso em 2I jul. 2017.

BRASIL, Medida Provisória no 1.039 , de 18 de Março de 202ı.Diário Oficial da União. https://www.in.gov.br/en/web/dou/-/medida-provisoria-n-I.039-de-I8-demarco-de-2021-309292254.

GARCIA, G. F. B. Curso de Direito do Trabalho. II ${ }^{\circ}$.ed. Rio de Janeiro: Forense, 2014 .

INSTITUTO BRASILEIRO DE GEOGRAFIA E ESTATÍSTICA- IBGE. em 28 de Janeiro de 2021.Disponível em https://observatoriozsetor.org.br/noticias/brasilperde-15-milhao-de-postos-de-trabalho-domestico-na-pandemia/

RESENDE, R. Direito do Trabalho: Esquematizado. 6o.ed. São Paulo: Método, 2016.

SOUZA JUNIOR, Antonio Umberto de. O novo direito do trabalho doméstico. São Paulo: Saraiva, 2015.

LEITE, Carlos Henrique Bezerra; LEITE, Laís Durval; LEITE, Letícia Durval. A nova lei do trabalho doméstico. São Paulo: Saraiva, 2015.

LEITE. Carlos Henrique Bezerra Curso de direito do trabalho - 9. ed. - São Paulo : Saraiva Educação, 2018. 
BRASIL, Lei Complementar $\mathrm{n}^{\mathrm{o}}$ i5o de or.06.2015. PODER EXECUTIVO Disponível em: http://www.normaslegais.com.br/legislacao/Lei-complementar-I5o2015.htm

AVELINO, Mario. O futuro do Emprego Doméstico no Brasil. Disponível em: Acesso em: 04 de Abril de 2021. https://www.domesticalegal.com.br/tag/marioavelino/

TUPINAMBÁ, Carolina.(Coord). As novas relações trabalhistas e o futuro do direito do trabalho-novidades derivadas da pandemia da covid-ı e da crise de 2020 . Editora Forum. Belo Horizonte- 202I.

BRASIL. Decreto-Lei 5.452 de Io de maio de 1943. Consolidação das Leis do trabalho, https://www.jusbrasil.com.br/topicos/I0758212/paragrafo-2-artigo-74-do-decreto-lein-5452-de-oi-de-maio-de-1943

BRASIL, Lei no 12.964/2014. De o8 de Abril de 2014. Altera a Lei no 5.859, de II de dezembro de 1972, para dispor sobre multa por infração à legislação do trabalho doméstico. Disponível em: http://www.planalto.gov.br/ccivil_03/_ato2orI2014/2014/lei/li2964.htm

BRASIL, Lei no 10.208 de 23 de Março de 200.. Planalto. Disponível em: http://www.planalto.gov.br > ccivil_03 > leis > leis_20oI

BRASIL. Emenda constitucional № 72, DE 2 DE ABRIL DE 2013. Presidência da República. Disponível em:

http://www.planalto.gov.br/ccivil_03/constituicao/emendas/emc/emc72.htm

BRASIL, LEI № 5.859, de II de dezembro de 1972; Legislação. Disponível em: https://www2.camara.leg.br/legin/fed/lei/1970-1979/lei-5859-II-dezembro-1972358025-publicacaooriginal-I-pl.html

BRASIL, Decreto-lei no 3.078, de 27 de fevereiro de 1941.LEGISLÇAO. Disponível em: https://www2.camara.leg.br/legin/fed/declei/1940-1949/decreto-lei-3078-27fevereiro-I94I-4I3020-publicacaooriginal-I-pe.html 